\title{
SUV4-20 activity in the preimplantation mouse embryo controls timely replication
}

\author{
André Eid, ${ }^{1}$ Diego Rodriguez-Terrones, ${ }^{2}$ Adam Burton, ${ }^{1,2}$ and Maria-Elena Torres-Padilla ${ }^{1,2}$ \\ ${ }^{1}$ Institut de Génétique et de Biologie Moléculaire et Cellulaire, U964, Centre National de la Recherche Scientifique (CNRS)/ \\ Institut National de la Santé et de la Recherche Médicale (INSERM), F-67404 Illkirch, CU de Strasbourg, France; ${ }^{2}$ Institute of \\ Epigenetics and Stem Cells, Helmholtz Zentrum München, D-81377 München, Germany
}

Extensive chromatin remodeling after fertilization is thought to take place to allow a new developmental program to start. This includes dynamic changes in histone methylation and, in particular, the remodeling of constitutive heterochromatic marks such as histone H4 Lys20 trimethylation (H4K20me3). While the essential function of H4K20me1 in preimplantation mouse embryos is well established, the role of the additional H4K20 methylation states through the action of the SUV4-20 methyltransferases has not been addressed. Here we show that Suv4$20 \mathrm{~h} 1 / \mathrm{h} 2$ are mostly absent in mouse embryos before implantation, underscoring a rapid decrease of H4K20me3 from the two-cell stage onward. We addressed the functional significance of this remodeling by introducing Suv4-20h1 and Suv4-20h2 in early embryos. Ectopic expression of Suv4-20h2 leads to sustained levels of H4K20me3, developmental arrest, and defects in S-phase progression. The developmental phenotype can be partially overcome through inhibition of the ATR pathway, suggesting that the main function for the remodeling of H4K20me3 after fertilization is to allow the timely and coordinated progression of replication. This is in contrast to the replication program in somatic cells, where $\mathrm{H} 4 \mathrm{~K} 20 \mathrm{me} 3$ has been shown to promote replication origin licensing, and anticipates a different regulation of replication during this early developmental time window.

[Keywords: mouse embryo; Suv4-20; heterochromatin; replication stress]

Supplemental material is available for this article.

Received August 11, 2016; revised version accepted November 7, 2016.

Fertilization of the oocyte by the sperm results in the formation of a totipotent zygote that has the ability to generate all extraembryonic and embryonic tissues necessary for development. The earliest stages of development prior to implantation are of critical importance for setting up the first embryonic lineages to generate an embryo competent for implantation. Therefore, a central question in biology is the defining role of the organization of the chromatin and its architecture during the first cell divisions and how they enable changes in cellular plasticity and fate.

In mice, preimplantation development is characterized by a distinctive atypical state of chromatin signatures, with many histone post-translational modifications (PTMs) reduced or absent after fertilization. In addition, the paternal and maternal chromatin remain physically segregated in two separate pronuclei that maintain distinctive chromatin marks, with the maternal chromatin containing most constitutive heterochromatin PTMs, while the paternal chromatin is enriched with PTMs of facultative heterochromatin, thought to substitute for the absence of constitutive heterochromatin therein

Corresponding author: torres-padilla@helmholtz-muenchen.de Article published online ahead of print. Article and publication date are online at http://www.genesdev.org/cgi/doi/10.1101/gad.288969.116. (for review, see Burton and Torres-Padilla 2014). The histone H4 Lys20 dimethylation and trimethylation (H4K20me2/3) are hallmarks of constitutive heterochromatin in somatic cells. H4K20me3 localizes primarily at centromeres, pericentromeres, and telomeres that are enriched in repetitive sequences and are gene-poor (Schotta et al. 2008). This is in contrast to H4K20 monomethylation (H4K20me1), which is one of the most abundant modifications on $\mathrm{H} 4$ and localizes to a wide variety of genomic regions in a cell cycle-dependent manner across somatic cells and in the early embryo (Barski et al. 2007; Jorgensen et al. 2007; Houston et al. 2008; Oda et al. 2010). While, in yeast, one single enzyme catalyzes the three H4K20 methylation states, in mammals, H4K20me1 is catalyzed by PR-Set7, and H4K20me2 and H4K20me3 are both catalyzed by the histone methyltransferases SUV4-20H1 and SUV4-20H2 (Kmt5b and Kmt5c, respectively) (Nishioka et al. 2002; Rice et al. 2002; Schotta et al. 2004, 2008). In the zygote, immediately after fertilization, H4K20me 3 is detected exclusively on the maternal pronucleus, where

(C) 2016 Eid et al. This article is distributed exclusively by Cold Spring Harbor Laboratory Press for the first six months after the full-issue publication date (see http://genesdev.cshlp.org/site/misc/terms.xhtml). After six months, it is available under a Creative Commons License (Attribution-NonCommercial 4.0 International), as described at http://creativecommons.org/licenses/by-nc/4.0/. 
it appears distributed mostly around ring-like structures formed by the nucleoli precursors (nucleolar-like bodies [NLBs]), which harbor the pericentromeric and centromeric regions (Probst et al. 2007; Wongtawan et al. 2011). Importantly, H4K20me3 is undetectable from the two-cell stage onward and remains so until the peri-implantation period (Wongtawan et al. 2011).

This transient loss of H4K20me3 is perplexing and raises two important questions. The only other cell types displaying the absence of H4K20me3 seem to be cancer cells with increased pluripotent capacity and proliferation activity, resulting in poor prognosis for patients (Fraga et al. 2005; Van Den Broeck et al. 2008; Schneider et al. 2011; Yokoyama et al. 2014). It is thus essential to understand how fluctuations in H4K20me3 levels impact cell proliferation and cellular potency. In addition, the lack of conventional constitutive heterochromatin in zygotes and twocell stage embryos has been linked to their characteristic nuclear organization and high chromatin dynamics, believed to support a higher developmental plasticity. However, whether changes in this atypical heterochromatin configuration play a functional role in developmental plasticity beyond a mere correlation has not been addressed.

Because the absence of H4K20me 3 correlates with the highest developmental potency, we hypothesize that lack of H4K20me3 is required for zygotic reprogramming to take place. We thus set out to address whether enforcing the maintenance of $\mathrm{H} 4 \mathrm{~K} 20 \mathrm{me} 3$ during preimplantation restricts developmental capacity and investigate how H4K20me3 relates to cellular proliferation in vivo. For this, we first determined that Suv4-20h1 and Suv4$20 h 2$ are only weakly expressed after fertilization. Accordingly, in order to achieve sustained maintenance of H4K20me3 throughout preimplantation development, we ectopically expressed Suv4-20h1 and Suv4-20h2. Our results show that ectopic expression of Suv4-20h2 is sufficient to enable global levels of H4K20me3. Suv4-20h2 displayed a markedly higher ability to restore H4K20me3 than Suv4-20h1, independently of changes in H3K9me3. Embryos expressing Suv4-20h2-but not Suv4-20h1-do not efficiently develop beyond the two-cell stage, indicating that the remodeling of $\mathrm{H} 4 \mathrm{~K} 20 \mathrm{me} 3$ is required for developmental progression. Suv4-20h2 expression led to a proliferation defect accompanied by replication abnormalities. Importantly, the developmental phenotype was partially rescued by inhibition of the ATR pathway, suggesting that H4K20me3 induces replication stress and Sphase arrest. Our results shed light on the functional role of the absence of $\mathrm{H} 4 \mathrm{~K} 20 \mathrm{me} 3$ during preimplantation development and suggest that, in contrast to somatic cells, H4K20me3 is incompatible with the timely progression of DNA replication of embryonic chromatin.

\section{Results}

Expression of H4K20 modifiers during preimplantation development

SUV4-20H1 and SUV4-20H2 are the two mammalian homologs of Drosophila Set8. In mammals, SUV4-20H2 has a slight preference for H4K20me3, but the combined knockout of Suv4-20h1/h2 completely abolishes H4K20me3 (Schotta et al. 2004, 2008), indicating that they are the major H4K20me3 methyltransferases in mammalian cells. We thus analyzed the expression of both genes by RT-qPCR in all stages of preimplantation development. The pattern of expression of both Suv4$20 h 1$ and Suv4-20h2 resembles that of maternally inherited transcripts, with higher levels in the zygote and a reduction at or after the two-cell stage (Supplemental Fig. S1). However, both enzymes are expressed at very low levels compared with the control housekeeping gene (Actinb), with Suv4-20h1 exhibiting lower levels of expression than Suv4-20h2 (Supplemental Fig. S1). A third enzyme, Smyd5, was reported to methylate H4K20 in vitro (Stender et al. 2012), although the contribution of SMYD5 to global H4K20me3 levels in vivo is unclear. We found that, in contrast to the two Suv4-20 enzymes, the expression of Smyd5 is strongly induced from the two-cell stage onward and is expressed continuously thereafter (Supplemental Fig. S1). Given the strong expression of SMYD5 during these developmental time periods, when H4K20me3 is undetectable on embryonic chromatin (Wongtawan et al. 2011), it is unlikely that SMYD5 contributes to the global remodeling of H4K20me3 after fertilization. Note that there are no specific antibodies available for SUV4-20H1, SUV4-20H2, or SMYD5 (our unpublished observations), and therefore our analysis for these three enzymes focuses on mRNA exclusively. To date, only one demethylase has been shown to be able to act on H4K20me3 in vitro: PHF2, which can also demethylate H3K9me1 (Wen et al. 2010; Stender et al. 2012). RT-qPCR showed that the mRNA for Phf2 is abundant in the zygote, in comparison with later stages, as Phf2 is practically absent from the eight-cell stage onward (Supplemental Fig. S1), suggesting that Phf2 mRNA is inherited maternally but degraded after fertilization. Immunostaining revealed that PHF2 is present throughout all stages of preimplantation development concomitantly with the absence of H4K20me3 (data not shown). While PHF2 may contribute toward keeping H4K20me3 practically absent from the embryonic chromatin, the results above suggest that low H4K20me3 levels throughout the cleavage stages is in part due to low expression of SUV4-20 methyltransferases.

\section{Expression of Suv4-20h2 results in accumulation of H4K20me3}

Given the above results, in order to maintain sustained H4K20me3 during preimplantation development, we chose to ectopically express Suv4-20h2 in zygotes, in particular because manipulating PHF2 levels may also directly affect H3K9me1. Zygotes were microinjected with mRNA for HA-tagged Suv4-20h2 in combination with mRNA for GFP as an injection control (Fig. 1A). Control groups included embryos injected with mRNA for GFP alone as well as noninjected embryos. Embryos were cultured until the late zygote stage and analyzed by immunofluorescence using an HA-antibody, which 

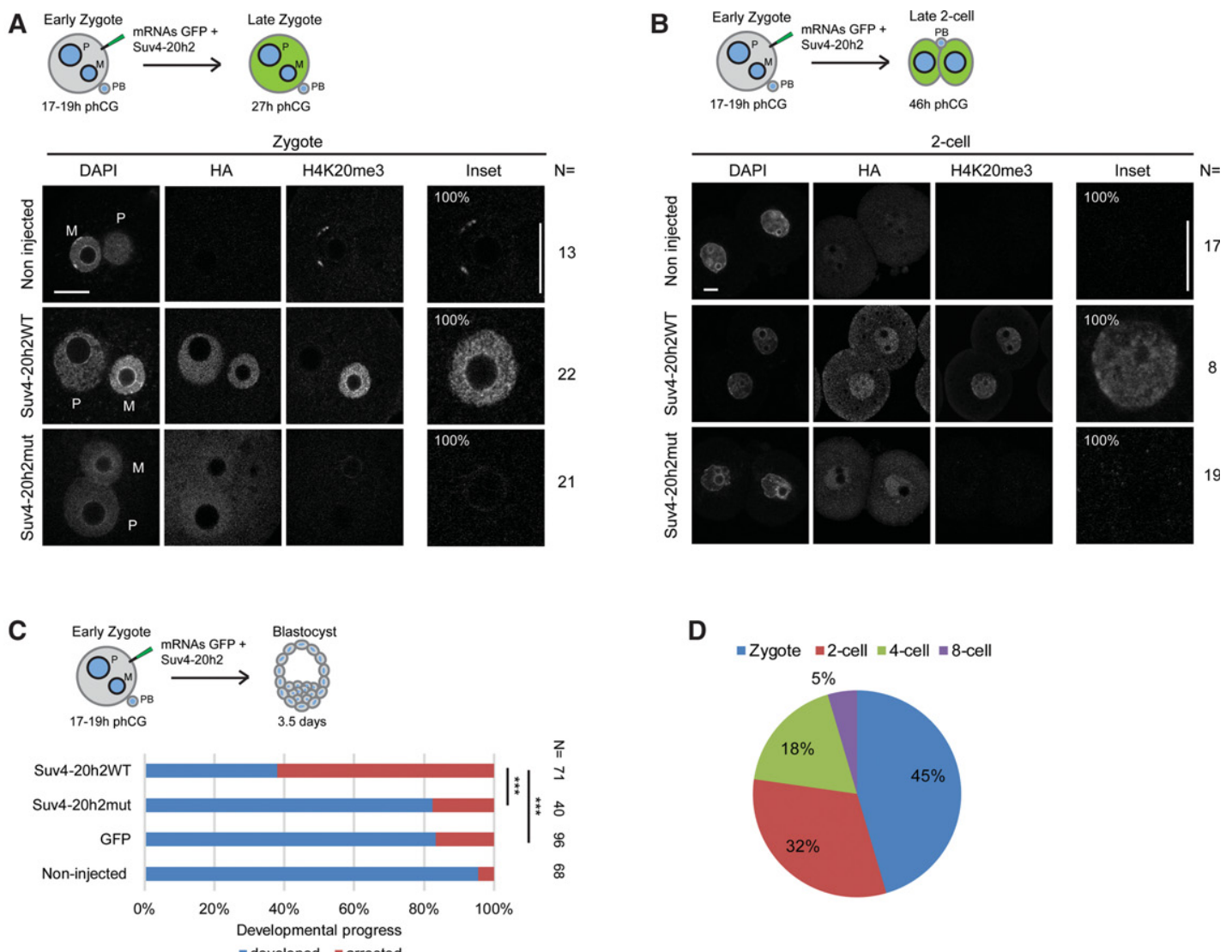

E

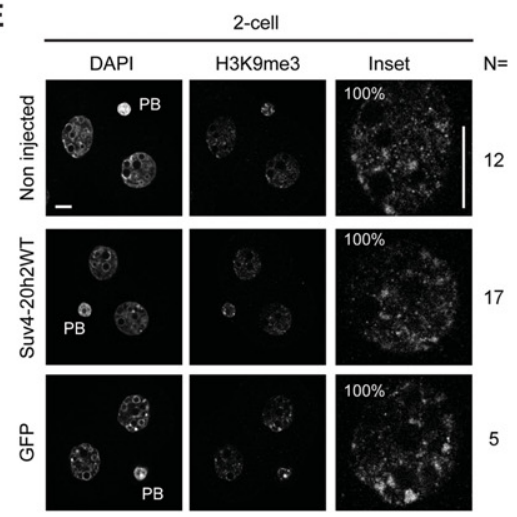

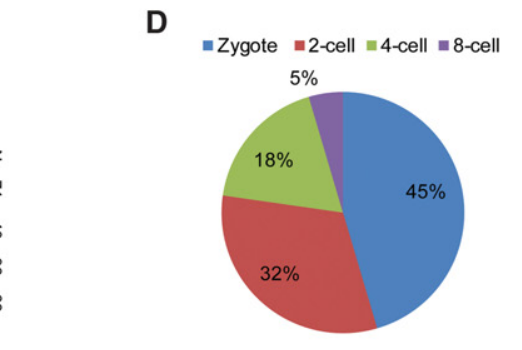

\section{$\stackrel{x}{2}$}

$\mathbf{F}$

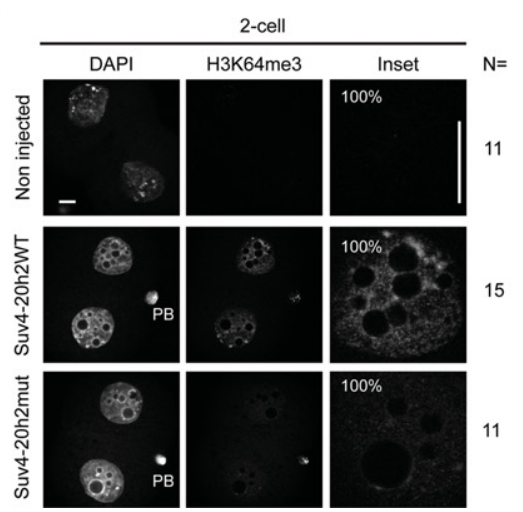

Figure 1. Maintenance of H4K20me3 through Suv4-20h2 ectopic expression blocks embryonic development prior to the two-cell stage. (A) A schematic representation of the experimental design is shown at the top. Zygotes between 17 and 19 h post-human chorionic gonadotropin (phCG) were microinjected with mRNA Suv4-20h2WT or Suv4-20h2mut in addition to GFP, cultured in KSOM (K-modified simplex optimized medium), and then fixed in 4\% formaldehyde (as indicated in the Material and Methods) at $27 \mathrm{~h}$ phCG. Representative images showing single Z-projections of confocal sections of noninjected, Suv4-20h2WT-injected, and Suv4-20h2mut-injected zygotes stained with DAPI, HA, and H4K20me3 antibodies. An inset of the maternal pronucleus is shown in the right panels. $N$ numbers are indicated at the right. (M) Maternal, $(\mathrm{P})$ paternal. Bars: inset, $5 \mu \mathrm{m}$; all others, $10 \mu \mathrm{m}$. $(B)$ Microinjections were performed as in $A$, except that embryos were fixed at $46 \mathrm{~h}$ phCG. Representative images showing single Z-projections of confocal sections of noninjected, Suv4-20h2WTinjected, and Suv4-20h2mut-injected two-cell stage embryos stained with DAPI, HA, and H4K20me3 antibodies. An inset of one of the two nuclei is shown in the right panels. $N$ numbers are indicated at the right. Bars: inset, $5 \mu \mathrm{m}$; all others, $10 \mu \mathrm{m}$. $(C)$ Zygotes were microinjected as in $A$ and cultured until the blastocyst stage. The number of embryos reaching the morula stage (developed) was quantified for noninjected, GFP alone-injected, Suv4-20h2mut-injected, and Suv4-20h2WT-injected embryos. Total numbers of embryos are indicated next to the plot. Statistical testing was performed using the $N-1$ two-proportion test for comparing independent proportions. $\left({ }^{* *}\right) P<0.0001$. $(D)$ Pie chart showing the distribution of arrested Suv4-20h2WT-injected embryos by stage. $(E, F)$ Zygotes were microinjected as in $A$ and analyzed with an $\mathrm{H} 3 \mathrm{~K} 9 \mathrm{me} 3(E)$ or H3K64me3 $(F)$ antibody at the two-cell stage. Representative images showing single $Z$ projections of confocal sections of noninjected, Suv4-20h2WT-injected, and GFP-injected or Suv4-20h2mut-injected embryos. An inset of one of the two nuclei is shown in the right panels. $N$ numbers are indicated. Bars: inset, $5 \mu \mathrm{m}$; all others, $10 \mu \mathrm{m}$. (PB) Polar body. 
revealed that SUV4-20H2 was efficiently translated and localized to both maternal and paternal pronuclei (Fig. 1A). In nonmanipulated embryos, H4K20me3 is detected only around the NLBs and in the nuclear periphery at $4^{\prime}$ 6-diamidino-2-phenylindole (DAPI)-rich regions in the maternal pronucleus and is undetectable in the paternal chromatin (Fig. 1A, noninjected) (Kourmouli et al. 2004; Wongtawan et al. 2011). Expression of Suv4-20h2 resulted in a clear increase in H4K20me3 levels in the maternal pronucleus but not in the paternal pronucleus (Fig. 1A). This observation was surprising considering that SUV4$20 \mathrm{H} 2$ was distributed equally between both pronuclei and suggests that SUV4-20H2 is unable to modify the levels of H4K20me3 on the paternal chromatin in zygotes, perhaps due to the absence of $\mathrm{H} 3 \mathrm{~K} 9 \mathrm{me} 3$ (Lange et al. 2013). At the two-cell stage, SUV4-20H2 as well as H4K20me3 were readily detected in the nuclei of both blastomeres at levels comparable with those in zygotes (Fig. 1B; Supplemental Fig. S1D). This was in contrast to noninjected embryos, where there were no detectable levels of H4K20me3, in agreement with earlier findings (Fig. 1B). The distribution of H4K20me3 throughout twocell stage nucleus, as opposed to only half of the nucleus, indicates that SUV4-20H2 can methylate both paternal and maternal chromosomes at this stage, suggesting that methylation on the paternal chromatin is delayed in comparison with the maternal one, which takes place in the zygote.

To test for the specific effects of the methyltransferase activity of SUV4-20H2, we generated a mutant in the SET domain. The SET domain is shared across several other histone methyltransferases, including SUV3-9H1, in which a mutation in the amino acid sequence (NHDC) abrogates its catalytic activity (Rea et al. 2000; Lachner et al. 2001). We therefore generated a SUV4-20H2 construct in which the corresponding NHDC motif was replaced by AAAG. The resulting mutant protein is referred to here as SUV4-20H2MUT, while the wild type is referred to here as SUV4-20H2WT. We microinjected early zygotes as above with mRNA for Suv4-20h2mut and GFP and analyzed embryos at the late zygote stage. The AAAG mutation did not affect the localization of SUV4-20H2MUT (which remained evenly distributed in both pronuclei) but efficiently abolished the methyltransferase activity of SUV4-20H2, since expression of SUV4-20H2MUT did not lead to an increase in H4K20me3 levels in either the maternal or paternal pronucleus (Fig. 1A). Likewise, levels of H4K20me3 remained low in two-cell stage embryos expressing SUV4-20H2MUT, similar to control embryos (Fig. 1B).

Our results show that SUV4-20H2WT efficiently increases H4K20me3 levels in vivo, allowing us to sustain H4K20me3 levels during preimplantation development.

\section{H4K20me3 is incompatible with preimplantation development}

We next addressed whether embryos displaying sustained H4K20me3 can develop normally. Embryos were microinjected with mRNA for Suv4-20h2WT as above and cultured for $3 \mathrm{~d}$ until the blastocyst stage. As controls, we used noninjected embryos, embryos microinjected with GFP mRNA alone, and embryos expressing Suv4$20 h 2 M U T$ in combination with GFP. Control embryos showed robust development, with $95.5 \%, 83.3 \%$, and $82.5 \%$ developing to the morula stage for the noninjected embryos $(n=68)$ or embryos expressing GFP $(n=96)$ and SUV4-20H2mut ( $n=40$ ), respectively (Fig. 1C). These percentages reflect typical developmental rates obtained in these assays (Santenard et al. 2010; Jachowicz et al. 2013). In contrast, embryos expressing SUV4-20H2WT displayed a strikingly lower developmental rate $(38 \% ; n=71)$ (Fig. 1C). Since the SUV4-20H2MUT did not exhibit a developmental delay, this indicates that the developmental phenotype of the SUV4-20H2WT embryos is due to its histone methyltransferase activity. Thus, we conclude that the embryonic arrest observed for SUV4-20H2WT embryos is most likely due to the presence of H4K20me3, suggesting that the removal of this heterochromatic mark is a requisite for preimplantation development.

Next, we asked whether the developmental phenotype upon expression of SUV4-20H2WT at the zygote stage is specific to that stage exclusively. For this, we asked whether expression of SUV4-20H2WT at a different stage results in a similar cellular arrest. We introduced mRNA for Suv4-20h2WT in combination with GFP-or with mRNA for GFP alone as a negative control-in a single two-cell stage blastomere (Supplemental Fig. S2A). Expression of SUV4-20H2WT led to an increase in H4K20me3 levels in the injected cell in two-cell embryos (Supplemental Fig. S2B), which developed until the blastocyst stage. However, a detailed analysis of the number of cells in these embryos revealed a more limited cell progeny in SUV420H2WT-expressing blastomeres compared with the negative control (GFP-only) (Supplemental Fig. S2C), indicating that expression of SUV4-20H2WT in two-cell embryos leads to a cellular proliferation defect. Immunostaining of these embryos showed that cell arrest was often accompanied by nuclear fragmentation (Supplemental Fig. S2D). In conclusion, SUV4-20H2-mediated H4K20me3 leads to cell proliferation arrest in preimplantation embryos independently of the developmental stage.

\section{Sustained H4K20me3 results in developmental failure prior to the two-cell stage}

To understand the mechanism behind the developmental arrest in Suv4-20h2WT-expressing embryos, we dissected the developmental stages at which embryos arrest. Most embryos arrested at the zygote and two-cell stages $145 \%$ and $32 \%$, respectively). The distribution of arrested embryos across preimplantation development suggests that H4K20me3 affects the earlier stages of development during which epigenetic reprogramming takes place. Thus, we first addressed whether maintenance of H4K20me3 perturbs other heterochromatic marks in zygotes and two-cell stage embryos. Analysis of $\mathrm{H} 3 \mathrm{~K} 9 \mathrm{me} 3$ revealed no global differences between noninjected, GFP-expressing, or Suv4-20h2WT-expressing embryos (Fig. 1E; Supplemental Fig. S3A), in line with the suggested model for 
heterochromatin establishment in which SUV39H1/ $\mathrm{H} 2$ acts upstream of SUV4-20H1/H2 (Schotta et al. 2004). Thus, increased H4K20me3 occurred without global changes in $\mathrm{H} 3 \mathrm{~K} 9 \mathrm{me} 3$, allowing us to distinguish between phenotypic effects of the typical "H3K9me3-directed" heterochromatin and those effects specific to changes in H4K20me3.

The distribution of H3K64me3, another PTM of constitutive heterochromatin, strongly resembles that of H4K20me3 (Daujat et al. 2009). H3K64me3 is present in the maternal pronucleus but is undetectable from the two-cell stage onward. In agreement with this, H3K64me3 was undetectable in noninjected embryos at the two-cell stage (Fig. 1F). In contrast, SUV4-20H2WT embryos showed a marked increase in $\mathrm{H} 3 \mathrm{~K} 64 \mathrm{me} 3$ in two-cell stage nuclei, in contrast to SUV4-20H2MUT embryos, where H3K64me3 was not detected (Fig. 1F; Supplemental Fig. S3B). This observation is surprising considering that double Suv4-20h1/Suv4-20h2 knockout mouse embryonic fibroblasts (MEFs) retain H3K64me3, which had led to the suggestion that H3K64me3 occurs independently of SUV4-20 activity (Lange et al. 2013). Thus, the interplay between H4K20me3 and H3K64me3 in the embryo may obey different regulatory mechanisms than in somatic cells, or, alternatively, de novo acquisition of H4K20me3 may affect H3K64me3.

\section{The developmental failure elicited by H4K2Ome3 is mediated by SUV4-2OH2}

Suv4-20h1 is the second mammalian homolog of Set8 and is expressed only weakly in the early embryo (Supplemental Fig. S1). To address whether the embryonic arrest observed following H4K20me3 maintenance is specific to the histone methyltransferase activity of SUV4-20H2, we undertook the same experimental approach as above with SUV4-20H1. When ectopically expressed, SUV4$20 \mathrm{H} 1$ displayed a nuclear localization similar to that of SUV4-20H2 at the zygote stage. However, SUV4-20H1 did not detectably increase levels of H4K20me3 at the zygote stage (Fig. 2A), and H4K20me3 levels increased only weakly at the two-cell stage (Fig. 2B), indicating that, in vivo, in the embryo, the catalytic activity toward H4K20me3 is higher for SUV4-20H2 than for SUV420H1. This is in agreement with previous suggestions from crystallography work (Southall et al. 2014). The low histone methyltransferase activity of SUV4-20H1 was lost upon mutating the NHDC sequence of its SET domain into AAAG, similar to SUV4-20H2 (Fig. 2B, SUV4-20H1MUT). Next, we monitored development of embryos expressing SUV4-20H1, similar to that of SUV4-20H2 (Fig. 2C). We microinjected early zygotes with either Suv4-20h1WT or Suv4-20h1MUT mRNA in combination with mRNA for GFP or with mRNA for GFP alone. Similarly, embryos expressing Suv4-20h1WT did not show a significant change in developmental progression $(n=78)$ (Fig. 2C). Indeed, their development rate to the blastocyst stage (66\%) was not significantly different from that of embryos expressing GFP alone $177 \%$; $P$ $=0.16)$. These observations indicate that the increase in
H4K20me3 from the zygote to the two-cell stage is a primary cause of the embryonic arrest and is mediated mainly by SUV4-20H2 histone methyltransferase activity.

The effect of SUV4-20H2 on gene expression during embryonic genome activation (EGA)

Deposition of H4K20me3 through SUV4-20H2 can cause RNA polymerase II ( $\mathrm{Pol}$ II) pausing. H4K20me3 has also been shown to repress gene expression in transformed cell lines by reducing H4K16 acetylation (H4K16ac) levels (Kapoor-Vazirani et al. 2011). In mice, the first wave of EGA takes place in the zygote, and the second wave, with a higher transcriptional activity, takes place at the two-cell stage (Flach et al. 1982; Bensaude et al. 1983; Aoki et al. 1997). Given that most SUV4-20H2 embryos arrested at the zygote and two-cell stages, we thus investigated whether the increase in H4K20me3 resulted in suppression of EGA in these embryos, which could potentially explain the developmental arrest. To evaluate global levels of gene expression, we pulsed embryos with EU (5ethynyl uridine) at the late two-cell stage at a time point corresponding to the late phase of transcription during EGA (Fig. 3A). Noninjected and SUV4-20H2MUT embryos showed a similar distribution of EU pattern, indicating that SUV4-20H2MUT does not compromise EGA, with $85 \%(n=13)$ and $94 \%(n=18)$ of embryos displaying active transcription, respectively (Fig. 3A,B). A significant proportion of two-cell stage embryos expressing SUV4$20 \mathrm{H} 2 \mathrm{WT}(61 \%, n=18)$ also displayed active transcription (Fig. 3B). Nevertheless, it seems that most embryos displayed lower transcriptional activity, since only $22 \%$ of SUV4-20H2 embryos showed high levels of EU incorporation, in comparison with $>50 \%$ for the noninjected and SUV4-20H2MUT groups (Fig. 3B). This suggests that sustained H4K20me3 does not prevent EGA but has some impact on global levels of transcription at the two-cell stage, which could partly explain the developmental block. Thus, to address whether SUV4-20WT embryos display specific changes in gene expression as opposed to a global or delayed effect on EGA, we profiled gene expression in individual embryos using a microfluidics Biomark approach, a robust and quantitative approach amenable to gene expression analysis from low amounts of material (Guo et al. 2010). We examined the expression of 45 genes in individual embryos across the four experimental groups: noninjected, SUV-420H1WT, SUV4-20H2WT, and SUV4-20H2MUT (Supplemental Fig. S5). The 45 genes analyzed were selected on the basis of (1) their known transcriptional activation at EGA, (2) their role in developmental progression and signaling during early development, and (3) their role in blastocyst formation (Supplemental Table S1). Principal component analysis (PCA) and unsupervised clustering analysis of these data revealed that expression of SUV4-20H2 did not induce significant changes in expression of the genes assessed, compared with the three control groups (Fig. 3C; Supplemental Fig. S5; Supplemental Table S2). Because most SUV4-20H2WT embryos displayed transcriptional activity, albeit at reduced rates, and the Biomark results 
Eid et al.
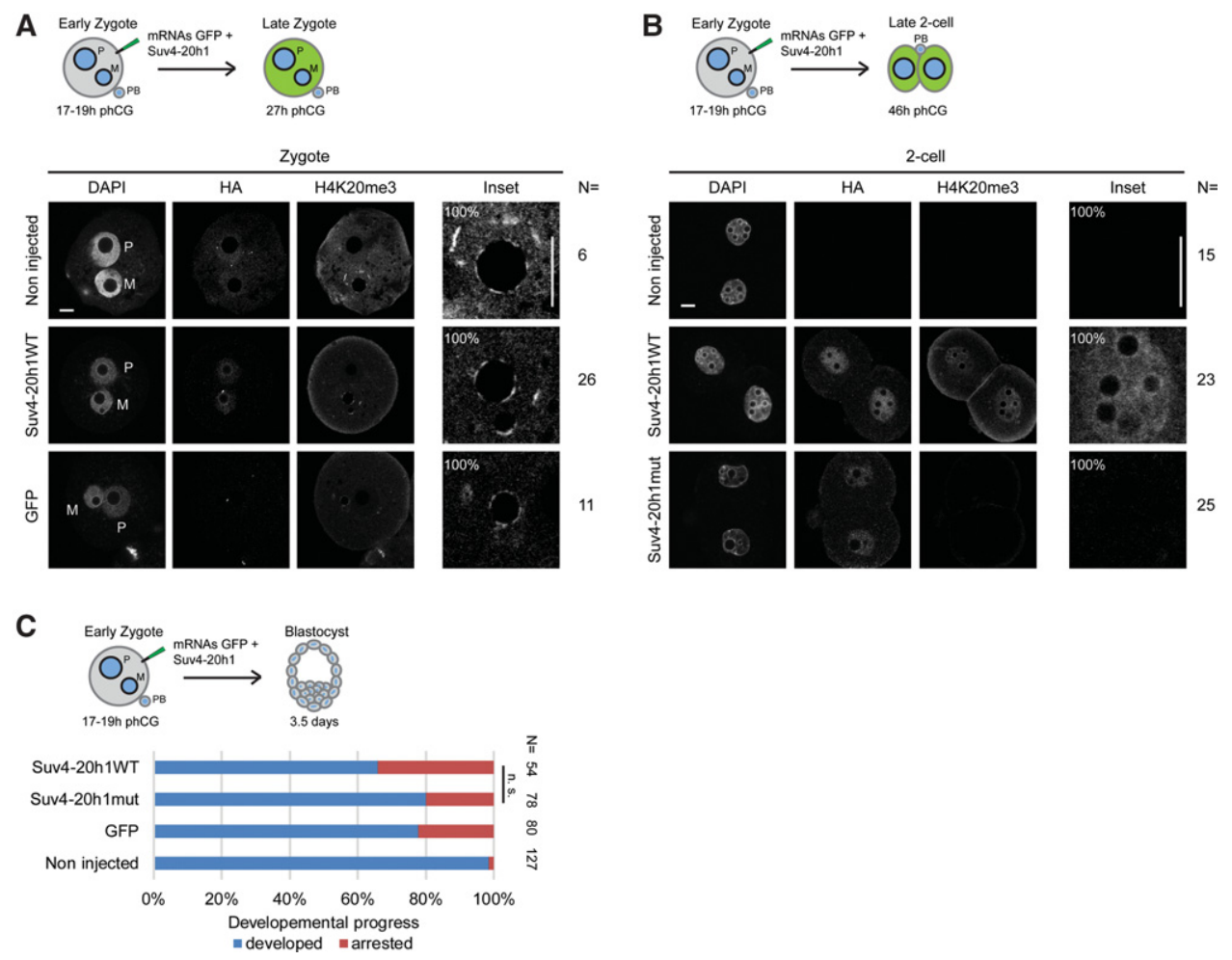

Figure 2. Ectopic expression of Suv4-20h1 does not arrest embryonic development or increase H4K20me3 levels in zygotes. (A) Schematic representation of the experimental design. Zygotes were microinjected with mRNA for Suv4-20h1WT or Suv4-20h1mut, cultured, and fixed for immunostaining using HA or H4K20me3 antibodies at $27 \mathrm{~h}$ phCG. Representative images show single $Z$-projections of confocal sections of noninjected, Suv4-20h1WT-injected, and GFP-injected zygotes. An inset of the maternal pronucleus is shown in the right panels. $N$ numbers are indicated. (M) Maternal; (P) paternal. Bars: inset, $5 \mu \mathrm{m}$; all others, $10 \mu \mathrm{m}$. $(B)$ Zygotes were microinjected with mRNA for Suv4-20h1WT or Suv4-20h1mut as in A, cultured, and analyzed at the two-cell stage. Representative images show single Z-projections of confocal sections of noninjected, Suv4-20h1WT-injected, and Suv4-20h1mut-injected embryos stained with DAPI, HA, and H4K20me3 antibodies. An inset of one of the two nuclei is shown in the right panels. $N$ numbers are indicated. Bars: inset, $5 \mu \mathrm{m} ;$ all others, $10 \mu \mathrm{m}$. $(C)$ Zygotes were microinjected with mRNA for Suv4-20h1WT or Suv4-20h1mut in combination with GFP and cultured until the blastocyst stage. The percentage of embryos that reached the blastocyst stage (developed) is plotted for noninjected, GFP-injected, Suv4-20h1mutinjected, and Suv4-20h1WT-injected embryos. The total number of embryos analyzed is indicated. Statistical testing was performed using the $N-1$ two-proportion test for comparing independent proportions. (n.s.) Not significant.

indicate that changes in specific gene expression were not significant, our observations altogether could also suggest a delay in the onset of transcriptional activation. Because the timing of transcriptional activation in embryos is closely related to that of replication, it therefore remains possible that the reduced transcriptional activity in SUV4-20H2WT embryos reflects a delay and/or a defect in S-phase progression.

\section{H4K20me3 perturbs developmental progression through replication in zygotes and two-cell stage embryos}

Previous reports have indicated that H4K20 methylation levels may play a role in the control of replication timing and origin licensing (Tardat et al. 2007, 2010; Oda et al. 2010; Vermeulen et al. 2010). Thus, we investigated whether the developmental arrest observed upon expression of SUV4-20H2WT could be due to a misregulation of $S$ phase. For this, we subjected embryos to an EdU (5-ethynyl-2'-deoxyuridine) pulse at the mid two-cell stage, the time at which most embryos are known to be in late S phase (Bolton et al. 1984). Because it is known that replication does not proceed synchronously across embryos, we further scored replication patterns as "late" or "early" according to whether they reflect a late $S$ phase (with low levels of EdU detected at the NLBs or the nuclear periphery) or an early-mid-S phase (where replication foci are visible and evenly distributed in the nucleus), respectively (Fig. 3D). As expected, most control embryos displayed a late replication pattern at this time point $(21$ out of 25) (Fig. 3D,E). Similarly, albeit with some delay presumably due to the microinjection procedure, most SUV4-20H2MUT embryos also displayed a late replication pattern (12 out of 20) (Fig. 3D,E). SUV4-20H2WT embryos instead mostly showed an early replication pattern, with $85 \%$ of embryos displaying high levels of EdU incorporation $(n=13)($ Fig. 3D,E). This observation points toward a misregulation of S-phase progression in SUV4$20 \mathrm{H} 2 \mathrm{WT}$ embryos and prompted us to further investigate the timing of S-phase initiation and completion. 


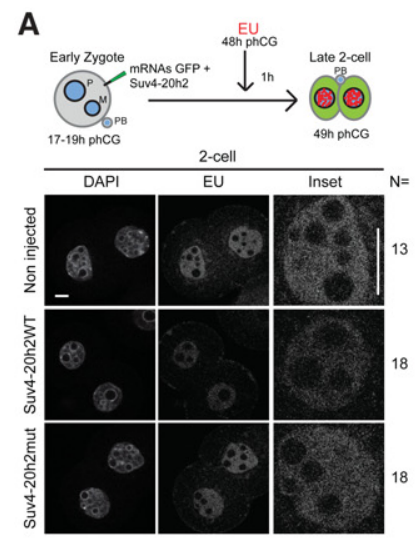

B

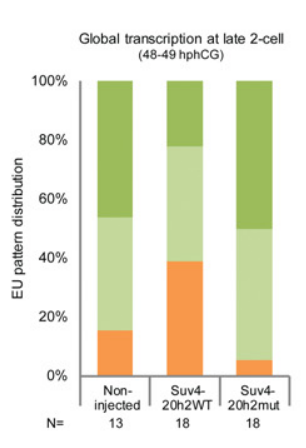

Ino EU $\equiv$ low EU $\equiv$ high EU

E

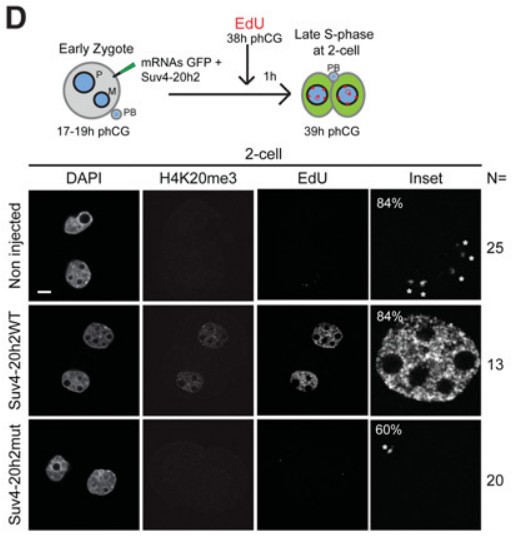

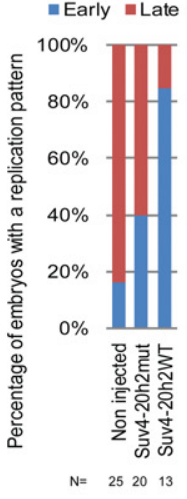

C
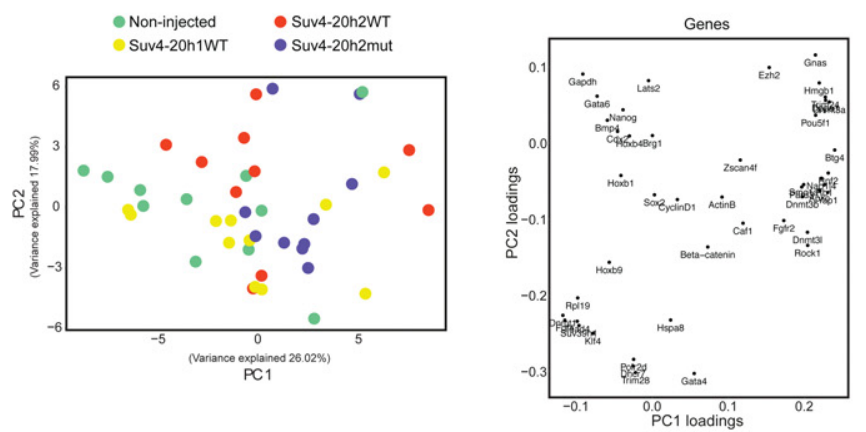

$\mathbf{F}$
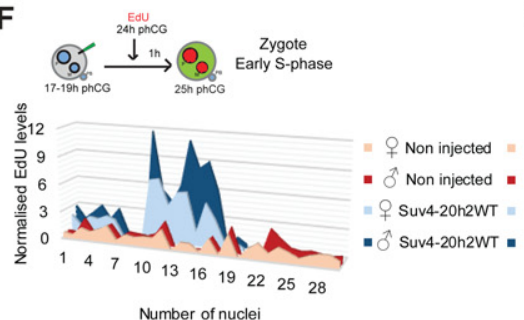

G

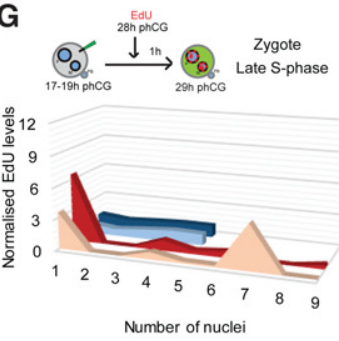

H

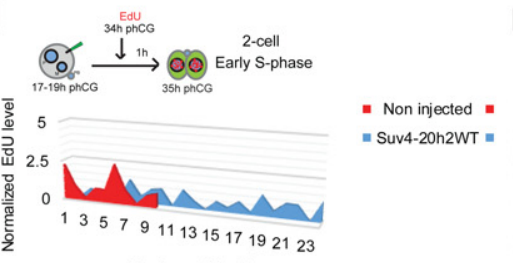

I

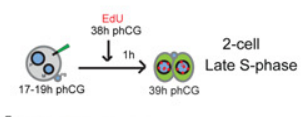

Ф 5

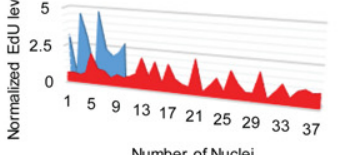

Figure 3. H4K20me3 affects replication progression. (A) Zygotes were microinjected with mRNA Suv4-20h2WT or Suv4-20h2mut, cultured until the two-cell stage, and pulsed with EU for $1 \mathrm{~h}$ at $48 \mathrm{~h}$ phCG. Representative images show single $Z$-projections of confocal sections of noninjected, Suv4-20h2WT-injected, and Suv4-20h2mut-injected embryos stained with DAPI and EU visualized by Click-iT reaction. An inset of one of the two nuclei is shown at the right. $N$ numbers are indicated. Bars: inset, $5 \mu \mathrm{m}$; all others, $10 \mu \mathrm{m}$. $(B)$. Distribution of EU patterns in late two-cell stage embryos. Embryos were divided into three groups based on their EU pattern: (1) no transcription (no EU detected), (2) low levels of transcription (as exemplified in A, Suv4-20h2WT), and (3) high levels of transcription (as shown in $A$, noninjected and Suv4-20h2mut). (C, right) Principal component (PC) projection of individual two-cell stage embryos based on the expression profiles of 45 genes detailed in Supplemental Table 1. Embryos are colored according to the experimental group. The first component (PC1) is shown on the $X$-axis, and the second component (PC2) is shown on the $Y$-axis. (Left) Principal component projection of gene loadings showing the weight of each gene in the analysis. (D) Zygotes microinjected with mRNA Suv4-20h2WT or Suv4-20h2mut were cultured until the two-cell stage, pulsed with 5-ethynyl-2'-deoxyuridine (EdU) for $1 \mathrm{~h}$ at $38 \mathrm{~h}$ phCG, fixed, and analyzed for EdU incorporation. Representative images showing single Z-projections of confocal sections of noninjected, Suv4-20h2WT-injected, and Suv4-20h2mut-injected embryos. An inset of one of the two nuclei is shown at the right. White asterisks indicate EdU labeling in noninjected and Suv420h2mut-injected embryos. N numbers are indicated. Bars: inset, $5 \mu \mathrm{m}$; all others, $10 \mu \mathrm{m}$. (E) Distribution of the replication patterns based on EdU labeling at 38-39 h phCG as shown in D. $(F, G)$ Normalized EdU levels measured in each pronucleus of noninjected and Suv420h2WT-injected zygotes at 24-25 h phCG $(F)$ and 28-29 h phCG $(G) .(H, I)$ Normalized EdU levels measured in each nucleus of noninjected and Suv4-20h2WT-injected two-cell stage embryos at 34-35 h phCG $(H)$ and 38-39 h phCG $(I)$.

We performed EdU labeling at four different time points that correspond to the onset and completion of $S$ phase in zygotes and two-cell stage embryos (early and late, respectively). Because of the limited number of embryos available per experiment, in these experiments, we used only noninjected embryos as negative controls. At the onset of replication in zygotes, all control embryos had undertaken replication and showed stable levels of EdU incorporation (Fig. 3F), with $80 \%$ of embryos having finished replication by $29 \mathrm{~h}$ post-human chorionic gonadotropin (phCG) injection (Fig. 3G). In contrast, while most
SUV4-20H2WT embryos undertook replication in a timely fashion $(90 \% ; n=20)$, the majority of them $(68 \%)$ showed significantly higher levels of EdU incorporation than noninjected embryos in both pronuclei (Fig. 3F), and all embryos maintained robust levels of EdU incorporation at $29 \mathrm{~h}$ phCG (Fig. 3G). EdU levels in embryos expressing GFP alone at the late zygote stage were not affected, compared with noninjected embryos (Supplemental Fig. S3C). These experiments suggest that while SUV4-20H2WT embryos enter S phase at a time similar to that of the controls, S-phase progression is delayed. 
Likewise, at the two-cell stage, control and SUV420H2WT embryos displayed similar levels of replication foci at the start of $\mathrm{S}$ phase ( $35 \mathrm{~h}$ phCG) (Fig. $3 \mathrm{H}$ ). However, SUV4-20H2WT embryos showed persisting high levels of EdU incorporation at $39 \mathrm{~h}$ phCG, while noninjected embryos had mostly completed $S$ phase at this time (Fig. 3I). These observations indicate a strong effect on S-phase progression in embryos with sustained H4K20me3 levels at the zygote and two-cell stages. Importantly, this phenotype correlates well with the timing and distribution of the embryonic arrest elicited upon ectopic expression of SUV4-20H2 (Fig. 1D).

Previous reports have shown that changes in the levels of H4K20me1 and the expression of PR-Set7 lead to an intra-S-phase checkpoint activation and cell cycle arrest (Tardat et al. 2007; Houston et al. 2008; Oda et al. 2009). Since H4K20 methylation is processive (Sims et al. 2006; Congdon et al. 2010), it is possible that the increased H4K20me3 levels upon ectopic expression of SUV420H2WT have repercussions on the levels of H4K20me1, and thus the developmental phenotype and the misregulation of $S$ phase may be due to changes in $\mathrm{H} 4 \mathrm{~K} 20 \mathrm{me} 1$ rather than an increase in H4K20me3. To address this, we analyzed levels of H4K20me1 in control embryos as well as embryos expressing SUV4-20H2WT or SUV4-20H2MUT at the two-cell stage during G2 phase, when H4K20me1 levels are highest (Fig. 4A). Expression of SUV4-20H2WT -but not of SUV4-20H2MUT-led to a reduction in H4K20me1 levels, suggesting that H4K20me1 is indeed used as a substrate for the higher methylation state (Fig. 4A; Supplemental Fig. S4A). To distinguish whether changes in H4K20me1 levels are related to the developmental phenotype elicited upon SUV4-20H2 expression, we analyzed H4K20me1 in embryos expressing SUV4$20 \mathrm{H} 1$, which do not display a developmental phenotype. Surprisingly, expression of SUV4-20H1WT showed a strong reduction of H4K20me1 (Fig. 4B) even though it did not lead to an increase in H4K20me3 (Fig. 2B). This suggests that SUV4-20H1WT converts H4K20me1 to H4K20me2. Indeed, the reduction in H4K20me1 upon expression of SUV4-20H1WT was dependent on its methyltransferase activity (Fig. 4B). However, in spite of multiple attempts, we were unable to identify a specific H4K20me2 antibody and therefore were unable to perform immunostaining for H4K20me2 (data not shown). Importantly, even though SUV4-20H1WT embryos show a reduction in $\mathrm{H} 4 \mathrm{~K} 20 \mathrm{me}$ l levels, they do not exhibit embryonic lethality or cell cycle arrest (Fig. 2C), in contrast to SUV4-20H2WT embryos, which show both reduction of H4K20me1 and developmental arrest (Fig. 1C). This observation suggests that reduction of $\mathrm{H} 4 \mathrm{~K} 20 \mathrm{me} 1$ levels may not explain the developmental phenotype observed upon expression of SUV4-20H2WT, leading us to conclude that the developmental arrest in SUV4-20H2WT embryos is mostly independent of changes in H4K20me1 levels. Indeed, while PR-Set7 loss leads to a G2/M arrest (Oda et al. 2009; Tardat et al. 2010), we did not detect changes in H3S10p in SUV4-20H2WT embryos compared with noninjected or SUV4-20H2MUT controls (Fig. 4C; Supplemental Fig. S4B). We aimed to address whether over- expression of PHF2 would rescue the developmental phenotype elicited by SUV4-20H2WT expression by reducing H4K20me3. However, under the experimental conditions tested, we were unable to detect a change in global H4K20me3 levels in spite of robust PHF2 expression (Supplemental Fig. S3D-F).

\section{SUV4-20H2-mediated embryonic arrest is partially rescued by inhibiting ATR}

All of our observations together suggest that the phenotypic arrest of embryos expressing SUV4-20H2WT is a result of a misregulation of DNA replication. H4K20 methylation can be a marker of DNA damage, and increased levels of H4K20me2/3 have been linked to the activation of the ATR pathway in cancer cells (Botuyan et al. 2006; Hajdu et al. 2011; Pei et al. 2011). We therefore hypothesized that sustained H4K20me3 could trigger DNA damage checkpoint activation during $S$ phase in embryos. We thus investigated the levels of $\gamma \mathrm{H} 2 \mathrm{~A}$.X, an indicator of DNA damage and replication stress, in addition to CHK1 and phosphorylated $\mathrm{CHK} 2$ (CHK2p), downstream effectors of the ATR/ATM pathway and S-phase checkpoint activation (Mechali et al. 2013). Immunostaining of twocell stage embryos at late $S$ phase using a $\gamma \mathrm{H} 2 \mathrm{~A}$.X antibody revealed diffuse nuclear accumulation of $\gamma \mathrm{H} 2 \mathrm{~A}$.X with a few foci in control noninjected embryos, in agreement with previous observations (Fig. 4D; Ziegler-Birling et al. 2009). We did not detect changes in the global levels of $\gamma \mathrm{H} 2 \mathrm{~A}$.X in embryos expressing either SUV4-20H2WT or SUV4-20H2MUT (Fig. 4D; Supplemental Fig. S4C), suggesting that sustained H4K20me3 levels do not cause dsDNA damage globally. In contrast, SUV4-20H2WT embryos showed higher levels of CHK1 in comparison with noninjected and SUV4-20H2MUT embryos during S phase (Fig. 4E; Supplemental Fig. S6A-D). In addition, CHK2p was also strongly induced in both pronuclei of SUV4-20H2WT embryos compared with noninjected and SUV4-20H2MUT embryos, which showed barely any signal for CHK2p (Fig. 4F; Supplemental Fig. S6EH). Note that we were unable to address levels of phosphorylated CHK1, since none of the commercially available CHK1p antibodies worked in immunostaining (data not shown). The increase in CHK1 and CHK2p indicates a potential signaling from DNA damage during $S$ phase upon expression of SUV4-20H2. Since H4K20me3 constitutes a direct platform for origin replication complex (ORC) loading (Beck et al. 2012), it is possible that increased origins of replication may be used or available in SUV4-20H2WT embryos. Indeed, this could explain the increase in EdU levels in these embryos at the beginning of $S$ phase (Fig. $3 \mathrm{~F}$ ) as well as the CHK1 and CHK2p increase through the generation of more ssDNA intermediates. The observation that CHK1 and CHK2p levels were higher in SUV4-20H2WT embryos suggested a checkpoint activation during $S$ phase. We reasoned that if embryos with sustained H4K20me3 levels upon expression of SUV4-20H2 arrest because of an S-phase checkpoint activation, we should be able to release the developmental arrest at least partially through inhibition of the ATR 
A

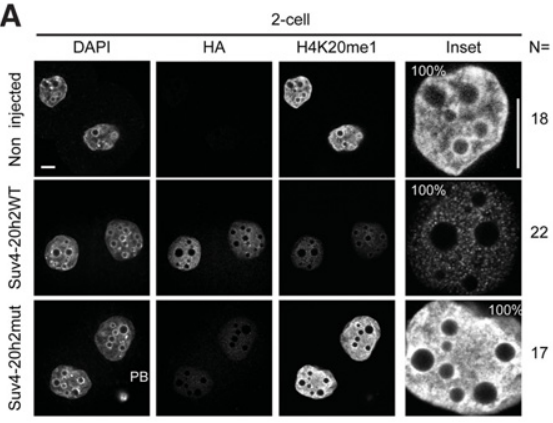

C
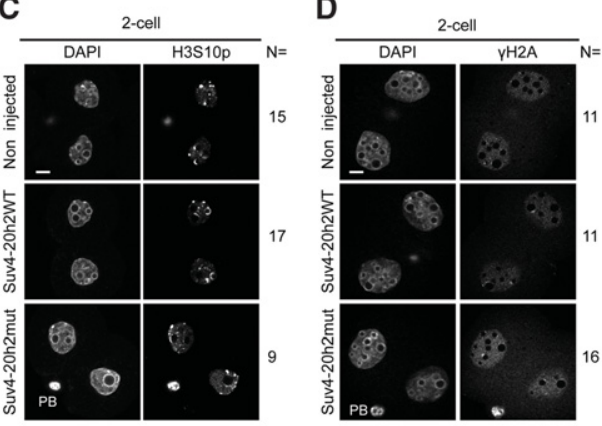

B

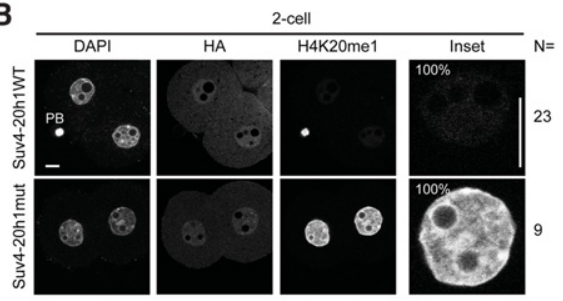

E Early replication at the Zygote stage (25n phCG)
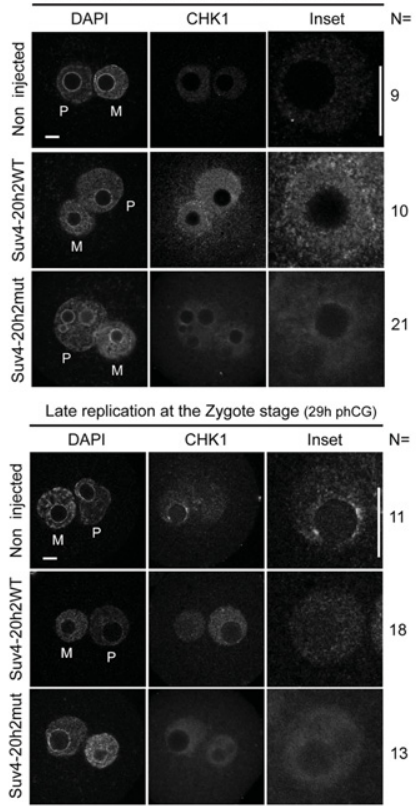

$\mathrm{F}$

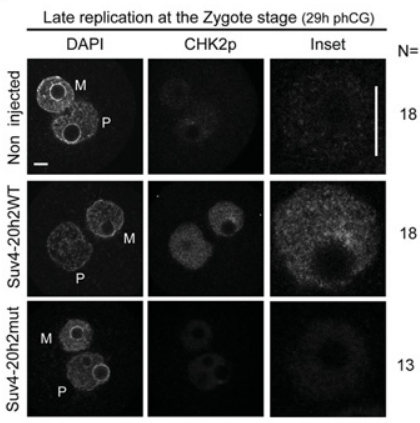

G
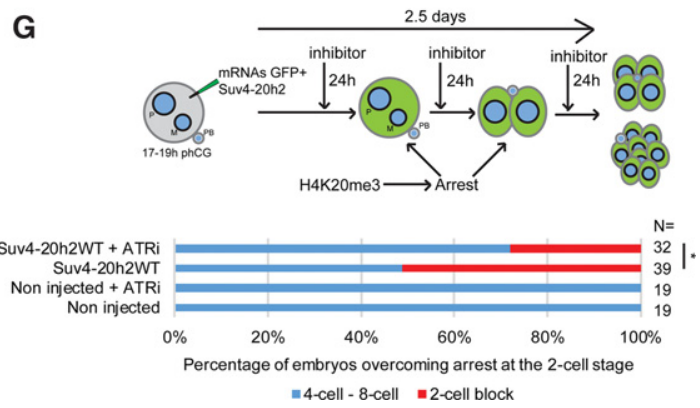

Figure 4. Embryonic arrest is partially rescued by inhibition of ATR. (A) Representative images of two-cell stage embryos analyzed at 46 $\mathrm{h}$ phCG with DAPI, HA, and H4K20mel antibodies. Single Z-projections of confocal sections are shown. An inset of one of the two nuclei is shown at the right. $N$ numbers are indicated. Bars: inset, $5 \mu \mathrm{m}$; all others, $10 \mu \mathrm{m}$. (PB) Polar gody. (B) Representative single $Z$-projections of confocal sections of Suv4-20h1WT-injected and Suv4-20h1mut-injected two-cell stage embryos stained at $46 \mathrm{~h}$ phCG with DAPI, HA, and H4K20mel antibodies. An inset of one of the two nuclei is shown in the right panels. $N$ numbers are indicated. Bars: inset, $5 \mu \mathrm{m} ;$ all others, $10 \mu \mathrm{m}$. (PB) Polar body. (C) Representative two-cell stage embryos acquired at $46 \mathrm{~h}$ phCG stained with DAPI and H3S10p antibodies, showing confocal single Z-projections of noninjected, Suv4-20h2WT-injected, and Suv4-20h2mut-injected embryos. N numbers are indicated. Bar, 10 m. (PB) Polar body. (D) Representative confocal single Z-projections of noninjected, Suv4-20h2WT-injected, and Suv4$20 \mathrm{~h} 2$ mut-injected two-cell stage embryos stained at $46 \mathrm{~h}$ phCG with DAPI and $\gamma \mathrm{H} 2 \mathrm{~A}$.X antibodies. $N$ numbers are indicated. Bar, $10 \mu \mathrm{m}$. (PB) Polar body. (E) Representative zygotes stained at $25 \mathrm{~h}$ phCG (early S phase) and $29 \mathrm{~h}$ phCG (late $\mathrm{S}$ phase) with DAPI and CHK1 antibodies, showing single confocal Z-projections of noninjected, Suv4-20h2WT-injected, and Suv4-20h2mut-injected embryos. Bars: inset, $5 \mu \mathrm{m}$; all others, $10 \mu \mathrm{m}$. (M) Maternal; (P) paternal. (F) Confocal single Z-projections of noninjected, Suv4-20h2WT-injected, and Suv4$20 \mathrm{~h} 2$ mut-injected zygotes acquired at $29 \mathrm{~h}$ phCG with DAPI and CHK2p antibodies. An inset of the maternal pronucleus is shown in the right panels. $N$ numbers are indicated. Bars: inset, $5 \mu \mathrm{m}$; all others, $10 \mu \mathrm{m}$. (M) Maternal; (P) paternal. For E and F, SUV420H2MUT and SUV4-20H2WT embryos were processed separately but in parallel with noninjected controls. $(G)$ A schematic representation of the experimental design is shown at the top. Zygotes between 17 and $19 \mathrm{~h}$ phCG were microinjected with mRNA for Suv420h2WT and GFP and cultured in the presence or absence of an ATR inhibitor (ATRi) until the eight-cell stage. A bar chart of the developmental progression until the four-cell stage is shown at the bottom. Statistical testing was performed using the $N-1$ two-proportion test for comparing independent proportions. $\left({ }^{*}\right) P<0.05$. 
pathway. To address this, embryos were injected as above with mRNA for Suv4-20h2WT and cultured in the presence of an ATR inhibitor (ATRi) from the late zygote stage (Fig. 4G). Since longer inhibition of ATR is known to block developmental progression (Brown and Baltimore 2000; Nakatani et al. 2015), we focused specifically on assessing the developmental block beyond the two-cell stage, which accounts for the majority of the phenotype $177 \%$ of SUV4-20H2 embryos arrest prior to the two-cell stage), by scoring embryos that reached the four-toeight-cell stage transition. As shown in Figure 4G, all noninjected embryos cultured in the presence of the ATRi reached the four-cell stage at a rate similar to that of noninjected embryos cultured without inhibitor. SUV420H2WT embryos treated with ATRi developed at significantly higher rates than SUV4-20H2WT embryos cultured without the inhibitor $(P<0.05 ; n=32)$ (Fig. 4G). Although not all embryos overcame the two-cell stage block upon inhibition of ATR, our results suggest that the developmental defects elicited from sustaining H4K20me3 levels are partially alleviated by inhibiting Sphase checkpoint activation. We conclude that the primary function of H4K20me3 remodeling after fertilization is to allow the timely progression of DNA replication through $\mathrm{S}$ phase. This is in contrast to the replication program in somatic cells, where replication occurs normally in the presence of H4K20me3 through ORC binding and anticipates a different regulation of replication during this developmental time window.

\section{Discussion}

Embryonic development requires a unique reprogramming mechanism to revert to a ground epigenetic state for a new developmental program to initiate. However, the repercussions of such remodeling at the molecular level are not understood. Zygotes and two-cell stage embryos exhibit a particular nuclear structure with distinctive and asymmetric chromatin signatures thought to be necessary for epigenetic reprogramming. Heterochromatic marks are unique identifiers of parental chromatin at fertilization, which are rapidly remodeled thereafter. To address the requirement for such a chromatin environment in vivo, we aimed to sustain the levels of one such PTM, H4K20me3, by expressing the corresponding methyltransferases (Suv4-20h1 and Suv4-20h2). Indeed, expression of such chromatin modifiers can be used to interrogate the system to shed light on the regulatory mechanisms of the early embryo by studying how they respond to such perturbations. We found that expression of Suv4-20h2 modifies H4K20 methylation by reducing H4K20me1 and increasing H4K20me3 levels and leads to embryonic arrest mostly before the two-cell stage. This embryonic arrest is dependent on the histone methyltransferase activity of SUV4-20H2. In addition, the developmental failure seems to derive from the specific activity of SUV4-20H2 and the sustained H4K20me3 levels, since expression of SUV4-20H1 does not result in developmental arrest or affect H4K20me3 levels markedly. While it is likely that the developmental arrest observed is due mainly to the H4K20me3 increase, we cannot rule out the possibility that changes in H3K64me3 levels could also potentially contribute to the developmental phenotype observed upon Suv4-20h2WT expression.

It is interesting to note that, in spite of ectopic SUV4$20 \mathrm{H} 2$ being detected in both pronuclei, H4K20me3 is only readily detected in the maternal pronucleus prior to the two-cell stage. It is possible that SUV4-20H2 is more active on chromatin already methylated with $\mathrm{H} 3 \mathrm{~K} 9 \mathrm{me} 3$, which is in line with the reinforcement loop of constitutive heterochromatin in somatic cells (Rea et al. 2000). In addition, because H4K20 methylation is processive and is among the modifications with the slowest rate of formation (Zee et al. 2010), it may take longer for SUV4-20H1 to reach full processivity in the absence of basal levels of H4K20me3 and/or H3K9me3. It is noteworthy that Suv4-20 enzymes can be targeted to chromatin through interaction with HP1, which mediates stable SUV4-20H2 binding synergistically (Schotta et al. 2004; Hahn et al. 2013). Because HP1 $\beta$ appears in the paternal chromatin only after S phase (Santos et al. 2005; Santenard et al. 2010) and because SUV4-20H1/H2 are known to function mostly in G1 (Zee et al. 2010), the lack of HP1 on the paternal pronucleus together with the processivity nature of SUV4-20 enzymes would explain why H4K20me3 is detected in the paternal chromatin only at the two-cell stage. SUV4-20H1 seems to display lesser activity toward H4K20me3 than SUV4-20H2 in the embryo. Although their SET domains are highly identical, SUV4-20H2 seems to have higher histone methyltransferase activity than SUV4-20H1 in vitro (Schotta et al. 2004). It is also possible that the longer nature of SUV4-20H1, which has 406 more amino acids than SUV4-20H2, may modulate its processivity. Strong overexpression of Suv4-20h2 in embryonic stem cells leads to increased chromatin compaction around chomocenters and consequent mitotic segregation defects (Hahn et al. 2013). However, we did not detect segregation defects in SUV4-20H2-expressing embryos.

The expression of SUV4-20H2 also leads to a misregulation of $S$ phase with increased replication sites, concomitant with activation of the ATR pathway (Fig. 5). We postulate that the subsequent activation of the intra-Sphase checkpoint is the cause of the cell cycle block. It is known that activation of ATR leads to a block of replication forks that exhibit ssDNA, but, in order to compensate for the delayed stalled forks undergoing repair, several dormant origins initiate replication (Gilbert 2007), which could explain the continuous EdU incorporation observed in the late $S$ phase in zygotes and two-cell stage embryos expressing SUV4-20H2WT. Alternatively, increased loading of ORC, favored by increased accessibility of its binder target, may facilitate the activation of additional origins, resulting in more extensive ssDNA and subsequent checkpoint activation (Fig. 5). In line with the suggestion of intra-S-phase checkpoint activation, chemical inhibition of ATR partially rescues the S-phase block and developmental capacity. The persistent embryonic arrest in a proportion of embryos could result from misregulation of gene expression independently of the cell cycle/S-phase 


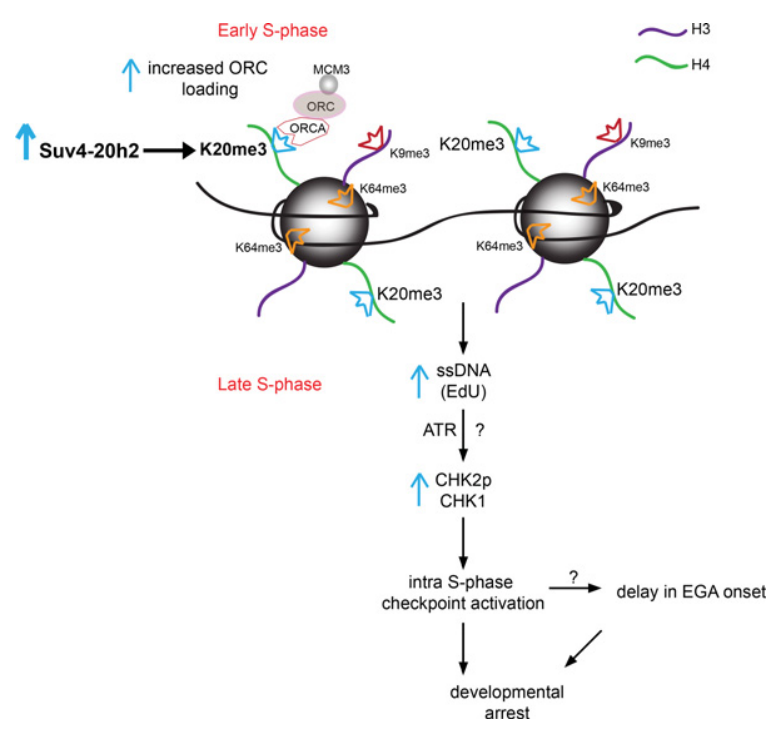

Figure 5. Working model for Suv4-20h2 and H4K20me3 effects on cell cycle progression in embryos. Expression of Suv4-20h2 establishes higher levels of H4K20me3, which is a known target of ORCA. In turn, ORCA can recruit ORC during early $S$ phase to replication origins. The increased levels of H4K20me3 lead to increased ORC loading, which would result in higher levels of ssDNA, as measured by EdU labeling. The increase in ssDNA can activate the ATR pathway, which promotes $\mathrm{CHK} 2$ phosphorylation, leading to the activation of the intra-S-phase checkpoint, causing a delay in cell cycle progression and developmental arrest.

progression at the two-cell stage, which might not be overcome by ATR inhibition. However, we could not formally distinguish effects on gene expression caused by developmental arrest.

Our results underscore the necessity for a chromatin signature in zygotes and two-cell embryos that is devoid of H4K20me3 and heterochromatin domains for the correct progression of replication. Indeed, it is possible that the relatively open chromatin structure at these stages is sufficient to enable regulated access to the replication machinery (Boskovic et al. 2014; Wu et al. 2016). More broadly, this anticipates a functional difference in the organization of the replication program between the early embryos and somatic cells.

\section{Materials and methods}

\section{Embryo collection, microinjection, and culture}

Embryos were collected from 5- to 7-wk-old F1 (C57BL/6J $\times$ CBA/ $\mathrm{H})$ superovulated females crossed with F1 males. Superovulation was induced by intraperitoneal injection of $5 \mathrm{IU}$ of pregnant mare serum gonadotropin (PMSG, Intervet) and 7.5 IU of hCG (Intervet) 46-48 h later. Zygotes were collected between 17 and $19 \mathrm{~h}$ phCG injection. mRNAs were transcribed in vitro from the pRN3P plasmid using the mMESSAGE mMACHINE kit (Ambion). All cDNAs were subcloned to include identical 5' caps and untranslated regions (UTRs; including Kozak) and a poly-T 3' UTR tail to ensure equivalent expression levels after mi- croinjection. Suv4-20h1 and Suv4-20h2 cDNA were obtained through a generous gift from G. Schotta (Ludwig-MaximiliansUniversität München, Munich), and Suv4-20h1mut was obtained through a generous gift from D. Beck (New York University, New York). Suv4-20h2mut was prepared by site-directed mutagenesis of Suv4-20h2 at asparagine 273 to cysteine 276 (NHDC) into AAAG (wild-type sequence CAACCATGACTG to mutated sequence CGCCGCTGCCGG) (Rea et al. 2000). Mouse Phf2 cDNA was obtained from $\mathrm{H}$. Qi (University of Iowa) and subcloned into the pRN3P plasmid. Zygotes were microinjected with 1-2 pL of the indicated mRNAs (700 ng/ $\mu \mathrm{L}$ for Suv4-20h1/Suv420h1mut/Suv4-20h2/Suv4-20h2mut/Phf2 or $250 \mathrm{ng} / \mu \mathrm{L}$ for Gfp) and allocated to the experimental groups at random. Embryos were cultured in KSOM (K-modified simplex optimized medium) microdrops under oil at $37^{\circ} \mathrm{C}$ and $5 \% \mathrm{CO}_{2}$ until they were fixed. Microinjections at the two-cell stage were performed in one of the blastomeres at random after embryo collection at 41-43 h phCG. Rescue experiments of the developmental block where performed by adding KSOM containing $10 \mu \mathrm{M}$ ATRi (Millipore, catalog no. 5.04972.0001) after injection and renewing the medium daily for $2 \mathrm{~d}$. Embryos were monitored and scored daily to determine developmental progression. Data were derived from at least three independent biological replicates. For statistical analysis of embryonic development, the $N-1$ two-proportion test for comparing independent proportions for small and large sample sizes was used, which is based on the $N-1 \chi^{2}$ test originally proposed by Pearson and recommended by Campbell. All experiments were performed after approval of the Ethics Committee of the Université de Strasbourg and according to French and European legislation on animal experimentation.

\section{EU and EdU incorporation}

Embryos were incubated with $50 \mu \mathrm{M}$ EU for $1 \mathrm{~h}$ at $48 \mathrm{~h}$ phCG treatment and then visualized by Click-iT chemistry (Life Technologies) as described in the manufacturer's instructions. Quantifications were performed as described in "Quantification of Fluorescence Intensity" (below). Embryos were incubated with $50 \mu \mathrm{M}$ EdU for $1 \mathrm{~h}$ at the times indicated in the figure legends and figure schemes and then visualized by Click-iT chemistry (Life Technologies) as described in the manufacturer's instructions.

\section{Immunostaining and confocal microscopy}

Fixation of freshly collected embryos from F1 superovulated, microinjected, and cultured embryos was performed as described (Torres-Padilla et al. 2006). Briefly, the zona pellucida was removed with Acid Tyrode solution followed by two washes in PBS and fixation in $4 \%$ paraformaldehyde, $0.04 \%$ Triton, $0.3 \%$ Tween 20 , and $0.2 \%$ sucrose at $37^{\circ} \mathrm{C}$ to ensure preservation of nuclear architecture. After permeabilization with $0.5 \%$ Triton in PBS, embryos were washed three times in PBSt $10.1 \%$ Tween 20 in PBS), quenched in $2.6 \mathrm{mg} / \mathrm{mL}$ freshly prepared ammonium chloride, washed twice in PBSt, blocked for 3-4 h or overnight at $4^{\circ} \mathrm{C}$ in blocking solution (BS: $3 \%$ BSA in PBSt), and incubated with primary antibodies in BS. The antibodies used were as follows: anti-HA (Abcam, 16B12), anti-H3K9me3 (Millipore, 07442), anti-H4K20me3 (Millipore, 07-463), anti-H3K9me3 (Millipore, 07-442), anti-H3K64me3 (generous gift from S. Daujat Institut de Génétique et de Biologie Moléculaire et Cellulaire, Illkirch), anti-H4K20me1 (Abcam, ab9051), anti-H3S10p (Abcam, ab5176), anti- $\gamma$ H2A.X (Millipore, 05-636), anti-CHK1 (Cell Signaling, 2G1D5), and anti-CHK2p (Cell Signaling, T68 2661S). After overnight incubation at $4^{\circ} \mathrm{C}$, embryos were washed three 
times in PBSt, blocked for $20 \mathrm{~min}$ in BS, and incubated for $3 \mathrm{~h}$ at room temperature in BS containing secondary antibodies labeled with Alexa fluorophores (Invitrogen). After washing twice in PBSt and once in PBS, embryos were mounted in VectaShield (Vector Laboratories) containing DAPI to visualize DNA. Confocal microscopy was performed on a $63 \times$ oil objective in a TCS SP5 inverted confocal microscope (Leica). $Z$-sections were taken every $0.5-1 \mu \mathrm{m}$. Image analysis was performed using the LAS-AF (Leica) and Imaris (Bitplane) software.

\section{Quantification of fluorescence intensity}

Confocal $z$-series stacks were reconstructed in three dimensions using Imaris software (Bitplane), and the pronuclei (zygote) or nuclei (two-cell stage) were segmented based on the DAPI channel. The average fluorescence intensity for the channel of interest within the segmented region was calculated after uniform background subtraction with a $95 \%$ confidence. The fluorescence intensity for each embryo was normalized to the average of the noninjected control group. The data were tested for normality using the Kolmogorov-Smirnov test. If the data were found to not be normally distributed, the Mann-Whitney $U$-test, a nonparametric test, was used.

\section{Gene expression analysis}

Control noninjected, Suv4-20h1WT-injected, Suv4-20h2WT-injected, and Suv4-20h2mut-injected two-cell stage embryos were washed in PBS and flash-frozen in liquid nitrogen in $5 \mu \mathrm{L}$ of $2 \times$ reaction buffer (CellsDirect One-Step qRT-PCR kit, Invitrogen) at $44 \mathrm{~h}$ phCG. TaqMan gene expression assays (20×; Applied Biosystems), previously tested using embryonic stem cell cDNA for amplification efficiency, were pooled to a final concentration of $0.2 \times$ for each of the 48 assays. To each of the single-cell samples in $2 \times$ reaction buffer, $2.5 \mu \mathrm{L}$ of $0.2 \times$ assay pool, $0.5 \mu \mathrm{L}$ of $\mathrm{RT} /$ Taq enzyme (CellsDirect qRT-PCR kit, Invitrogen), and $2.3 \mu \mathrm{L}$ of water were added. Cell lysis and sequence-specific reverse transcription were performed for $20 \mathrm{~min}$ at $50^{\circ} \mathrm{C}$. The reverse transcriptase was inactivated by heating for $2 \mathrm{~min}$ to $95^{\circ} \mathrm{C}$. Sequence-specific preamplification was performed by denaturing for $15 \mathrm{sec}$ at $95^{\circ} \mathrm{C}$ and then annealing and amplification for 4 min at $60^{\circ} \mathrm{C}$ for 18 cycles. The resulting cDNA was diluted fivefold before analysis with Universal PCR master mix and TaqMan gene expression assays (Applied Biosystems) in 48:48 Dynamic Arrays on a Biomark system (Fluidigm). $C_{\mathrm{t}}$ values were calculated from the system's software (Biomark real-time PCR analysis, Fluidigm). All raw $C_{\mathrm{t}}$ values were normalized to the assumed detection $C_{\mathrm{t}}$ level of 28 following the recommendation from Fluidigm technical support as in Guo et al. (2010) and Burton et al. (2013). $C_{\mathrm{t}}$ values $>28$ and those with curve qualities $<0.65$ were deemed unreliable measurements and were substituted with values of 28 . Whenever $C_{\mathrm{t}}$ values or quality scores were judged unreliable in one replicate but not the other, those of the successful replicate were kept. Additionally, all samples lacking expression of reference genes Actin- $b$ and Gapdh were removed from further analysis. The remaining $C_{\mathrm{t}}$ values were subtracted from 28 in order to achieve a scale in which zero corresponded to the lack of expression, and an increase of $1 \mathrm{U}$ indicated a doubling of the expression level (Guo et al. 2010; Burton et al. 2013). Violin plots of the resulting data set were generated using the ggplot $2 \mathrm{R}$ package. Statistical analysis was performed using the Mann-Whitney $U$-test. The PCA was performed using the pcaMethods R package, and variables were scaled to unit variance. All plotting was done in $\mathrm{R}$ using the ggplot2 package. The dendrogram clustering was generated in R using Euclidean distance.

\section{Acknowledgments}

We are grateful to Gunnar Schotta (Ludwig-Maximilians-Universität München) for providing antibodies, wild-type Suv4-20h1 and Suv4-20h2 constructs, and helpful discussions; David Beck (New York University) for providing the Suv4-20h1mut construct; and Hank H. Qi for the Phf2 cDNA. M.-E.T.-P. acknowledges funding from EpiGeneSys NoE, ERC-Stg "NuclearPotency," the EMBO Young Investigator Programme, the Schlumberger Foundation for Research and Education, and the Helmholtz Gesellschaft. A.E. was a recipient of a doctoral fellowship from the Ministère de 1'Enseignement Supérieur et de la Recherche and the Fondation pour la Recherche Médicale (FDT20150532012).

\section{References}

Aoki F, Worrad DM, Schultz RM. 1997. Regulation of transcriptional activity during the first and second cell cycles in the preimplantation mouse embryo. Dev Biol 181: 296-307.

Barski A, Cuddapah S, Cui K, Roh TY, Schones DE, Wang Z, Wei G, Chepelev I, Zhao K. 2007. High-resolution profiling of histone methylations in the human genome. Cell 129: 823-837.

Beck DB, Burton A, Oda H, Ziegler-Birling C, Torres-Padilla ME, Reinberg D. 2012. The role of PR-Set7 in replication licensing depends on Suv4-20h. Genes Dev 26: 2580-2589.

Bensaude O, Babinet C, Morange M, Jacob F. 1983. Heat shock proteins, first major products of zygotic gene activity in mouse embryo. Nature 305: 331-333.

Bolton VN, Oades PJ, Johnson MH. 1984. The relationship between cleavage, DNA replication, and gene expression in the mouse 2-cell embryo. J Embryol Exp Morphol 79: 139-163.

Boskovic A, Eid A, Pontabry J, Ishiuchi T, Spiegelhalter C, Raghu Ram EV, Meshorer E, Torres-Padilla ME. 2014. Higher chromatin mobility supports totipotency and precedes pluripotency in vivo. Genes Dev 28: 1042-1047.

Botuyan MV, Lee J, Ward IM, Kim JE, Thompson JR, Chen J, Mer G. 2006. Structural basis for the methylation state-specific recognition of histone $\mathrm{H} 4-\mathrm{K} 20$ by 53BP1 and Crb2 in DNA repair. Cell 127: 1361-1373.

Brown EJ, Baltimore D. 2000. ATR disruption leads to chromosomal fragmentation and early embryonic lethality. Genes Dev 14: 397-402.

Burton A, Torres-Padilla ME. 2014. Chromatin dynamics in the regulation of cell fate allocation during early embryogenesis. Nat Rev Mol Cell Biol 15: 723-734.

Burton A, Muller J, Tu S, Padilla-Longoria P, Guccione E, TorresPadilla ME. 2013. Single-cell profiling of epigenetic modifiers identifies PRDM14 as an inducer of cell fate in the mammalian embryo. Cell Rep 5: 687-701.

Congdon LM, Houston SI, Veerappan CS, Spektor TM, Rice JC. 2010. PR-Set7-mediated monomethylation of histone H4 lysine 20 at specific genomic regions induces transcriptional repression. J Cell Biochem 110: 609-619.

Daujat S, Weiss T, Mohn F, Lange UC, Ziegler-Birling C, Zeissler U, Lappe M, Schubeler D, Torres-Padilla ME, Schneider R. 2009. H3K64 trimethylation marks heterochromatin and is dynamically remodeled during developmental reprogramming. Nat Struct Mol Biol 16: 777-781.

Flach G, Johnson MH, Braude PR, Taylor RA, Bolton VN. 1982. The transition from maternal to embryonic control in the 2cell mouse embryo. EMBO J 1: 681-686.

Fraga MF, Ballestar E, Villar-Garea A, Boix-Chornet M, Espada J, Schotta G, Bonaldi T, Haydon C, Ropero S, Petrie K, et al. 
2005. Loss of acetylation at Lys16 and trimethylation at Lys20 of histone $\mathrm{H} 4$ is a common hallmark of human cancer. Nat Genet 37: 391-400.

Gilbert DM. 2007. Replication origin plasticity, taylor-made: inhibition vs. recruitment of origins under conditions of replication stress. Chromosoma 116: 341-347.

Guo G, Huss M, Tong GQ, Wang C, Li Sun L, Clarke ND, Robson P. 2010. Resolution of cell fate decisions revealed by singlecell gene expression analysis from zygote to blastocyst. Dev Cell 18: 675-685.

Hahn M, Dambacher S, Dulev S, Kuznetsova AY, Eck S, Worz S, Sadic D, Schulte M, Mallm JP, Maiser A, et al. 2013. Suv4$20 \mathrm{~h} 2$ mediates chromatin compaction and is important for cohesin recruitment to heterochromatin. Genes Dev 27: 859-872.

Hajdu I, Ciccia A, Lewis SM, Elledge SJ. 2011. Wolf-Hirschhorn syndrome candidate 1 is involved in the cellular response to DNA damage. Proc Natl Acad Sci 108: 13130-13134.

Houston SI, McManus KJ, Adams MM, Sims JK, Carpenter PB, Hendzel MJ, Rice JC. 2008. Catalytic function of the PRSet7 histone H4 lysine 20 monomethyltransferase is essential for mitotic entry and genomic stability. I Biol Chem 283: 19478-19488.

Jachowicz JW, Santenard A, Bender A, Muller J, Torres-Padilla ME. 2013. Heterochromatin establishment at pericentromeres depends on nuclear position. Genes Dev 27: 2427-2432.

Jorgensen S, Elvers I, Trelle MB, Menzel T, Eskildsen M, Jensen ON, Helleday T, Helin K, Sorensen CS. 2007. The histone methyltransferase SET8 is required for S-phase progression. I Cell Biol 179: 1337-1345.

Kapoor-Vazirani P, Kagey JD, Vertino PM. 2011. SUV420H2-mediated H4K20 trimethylation enforces RNA polymerase II promoter-proximal pausing by blocking hMOF-dependent H4K16 acetylation. Mol Cell Biol 31: 1594-1609.

Kourmouli N, Jeppesen P, Mahadevhaiah S, Burgoyne P, Wu R, Gilbert DM, Bongiorni S, Prantera G, Fanti L, Pimpinelli S, et al. 2004. Heterochromatin and tri-methylated lysine 20 of histone H4 in animals. J Cell Sci 117: 2491-2501.

Lachner M, O'Carroll D, Rea S, Mechtler K, Jenuwein T. 2001. Methylation of histone $\mathrm{H} 3$ lysine 9 creates a binding site for HP1 proteins. Nature 410: 116-120.

Lange UC, Siebert S, Wossidlo M, Weiss T, Ziegler-Birling C, Walter J, Torres-Padilla ME, Daujat S, Schneider R. 2013. Dissecting the role of $\mathrm{H} 3 \mathrm{~K} 64 \mathrm{me} 3$ in mouse pericentromeric heterochromatin. Nat Commun 4: 2233.

Mechali M, Yoshida K, Coulombe P, Pasero P. 2013. Genetic and epigenetic determinants of DNA replication origins, position and activation. Curr Opin Genet Dev 23: 124-131.

Nakatani T, Yamagata K, Kimura T, Oda M, Nakashima H, Hori M, Sekita Y, Arakawa T, Nakamura T, Nakano T. 2015. Stella preserves maternal chromosome integrity by inhibiting $5 \mathrm{hmC}$-induced $\gamma \mathrm{H} 2 \mathrm{AX}$ accumulation. EMBO Rep 16: 582589.

Nishioka K, Rice JC, Sarma K, Erdjument-Bromage H, Werner J, Wang Y, Chuikov S, Valenzuela P, Tempst P, Steward R, et al. 2002. PR-Set7 is a nucleosome-specific methyltransferase that modifies lysine 20 of histone $\mathrm{H} 4$ and is associated with silent chromatin. Mol Cell 9: 1201-1213.

Oda H, Okamoto I, Murphy N, Chu J, Price SM, Shen MM, Torres-Padilla ME, Heard E, Reinberg D. 2009. Monomethylation of histone H4-lysine 20 is involved in chromosome structure and stability and is essential for mouse development. Mol Cell Biol 29: 2278-2295.

Oda H, Hubner MR, Beck DB, Vermeulen M, Hurwitz J, Spector DL, Reinberg D. 2010. Regulation of the histone H4 monome- thylase PR-Set7 by CRL4(Cdt2)-mediated PCNA-dependent degradation during DNA damage. Mol Cell 40: 364-376.

Pei H, Zhang L, Luo K, Qin Y, Chesi M, Fei F, Bergsagel PL, Wang L, You Z, Lou Z. 2011. MMSET regulates histone H4K20 methylation and 53BP1 accumulation at DNA damage sites. Nature 470: 124-128.

Probst AV, Santos F, Reik W, Almouzni G, Dean W. 2007. Structural differences in centromeric heterochromatin are spatially reconciled on fertilisation in the mouse zygote. Chromosoma 116: 403-415.

Rea S, Eisenhaber F, O'Carroll D, Strahl BD, Sun ZW, Schmid M, Opravil S, Mechtler K, Ponting CP, Allis CD, et al. 2000. Regulation of chromatin structure by site-specific histone $\mathrm{H} 3$ methyltransferases. Nature 406: 593-599.

Rice JC, Nishioka K, Sarma K, Steward R, Reinberg D, Allis CD. 2002. Mitotic-specific methylation of histone H4 Lys 20 follows increased PR-Set7 expression and its localization to mitotic chromosomes. Genes Dev 16: 2225-2230.

Santenard A, Ziegler-Birling C, Koch M, Tora L, Bannister AJ, Torres-Padilla ME. 2010. Heterochromatin formation in the mouse embryo requires critical residues of the histone variant H3.3. Nat Cell Biol 12: 853-862.

Santos F, Peters AH, Otte AP, Reik W, Dean W. 2005. Dynamic chromatin modifications characterise the first cell cycle in mouse embryos. Dev Biol 280: 225-236.

Schneider AC, Heukamp LC, Rogenhofer S, Fechner G, Bastian PJ, von Ruecker A, Muller SC, Ellinger J. 2011. Global histone $\mathrm{H} 4 \mathrm{~K} 20$ trimethylation predicts cancer-specific survival in patients with muscle-invasive bladder cancer. BJU Int 108: E290-E296.

Schotta G, Lachner M, Sarma K, Ebert A, Sengupta R, Reuter G, Reinberg D, Jenuwein T. 2004. A silencing pathway to induce $\mathrm{H} 3-\mathrm{K} 9$ and H4-K20 trimethylation at constitutive heterochromatin. Genes Dev 18: 1251-1262.

Schotta G, Sengupta R, Kubicek S, Malin S, Kauer M, Callen E, Celeste A, Pagani M, Opravil S, De La Rosa-Velazquez IA, et al. 2008. A chromatin-wide transition to H4K20 monomethylation impairs genome integrity and programmed DNA rearrangements in the mouse. Genes Dev 22: 20482061.

Sims JK, Houston SI, Magazinnik T, Rice JC. 2006. A trans-tail histone code defined by monomethylated H4 Lys-20 and H3 Lys-9 demarcates distinct regions of silent chromatin. I Biol Chem 281: 12760-12766.

Southall SM, Cronin NB, Wilson JR. 2014. A novel route to product specificity in the Suv4-20 family of histone H4K20 methyltransferases. Nucleic Acids Res 42: 661-671.

Stender JD, Pascual G, Liu W, Kaikkonen MU, Do K, Spann NJ, Boutros M, Perrimon N, Rosenfeld MG, Glass CK. 2012. Control of proinflammatory gene programs by regulated trimethylation and demethylation of histone H4K20. Mol Cell 48: 28-38.

Tardat M, Murr R, Herceg Z, Sardet C, Julien E. 2007. PR-Set7-dependent lysine methylation ensures genome replication and stability through S phase. J Cell Biol 179: 1413-1426.

Tardat M, Brustel J, Kirsh O, Lefevbre C, Callanan M, Sardet C, Julien E. 2010. The histone H4 Lys 20 methyltransferase PRSet7 regulates replication origins in mammalian cells. Nat Cell Biol 12: 1086-1093.

Torres-Padilla ME, Bannister AJ, Hurd PJ, Kouzarides T, Zernicka-Goetz M. 2006. Dynamic distribution of the replacement histone variant $\mathrm{H} 3.3$ in the mouse oocyte and preimplantation embryos. Int J Dev Biol 50: 455-461.

Van Den Broeck A, Brambilla E, Moro-Sibilot D, Lantuejoul S, Brambilla C, Eymin B, Khochbin S, Gazzeri S. 2008. Loss of 
Eid et al.

histone H4K20 trimethylation occurs in preneoplasia and influences prognosis of non-small cell lung cancer. Clin Cancer Res 14: 7237-7245.

Vermeulen M, Eberl HC, Matarese F, Marks H, Denissov S, Butter F, Lee KK, Olsen JV, Hyman AA, Stunnenberg HG, et al. 2010. Quantitative interaction proteomics and genome-wide profiling of epigenetic histone marks and their readers. Cell 142: 967-980.

Wen H, Li J, Song T, Lu M, Kan PY, Lee MG, Sha B, Shi X. 2010. Recognition of histone H3K4 trimethylation by the plant homeodomain of PHF2 modulates histone demethylation. J Biol Chem 285: 9322-9326.

Wongtawan T, Taylor JE, Lawson KA, Wilmut I, Pennings S. 2011. Histone H4K20me3 and HP1 $\alpha$ are late heterochromatin markers in development, but present in undifferentiated embryonic stem cells. J Cell Sci 124: 1878-1890.
Wu J, Huang B, Chen H, Yin Q, Liu Y, Xiang Y, Zhang B, Liu B, Wang Q, Xia W, et al. 2016. The landscape of accessible chromatin in mammalian preimplantation embryos. Nature 534: 652-657.

Yokoyama Y, Matsumoto A, Hieda M, Shinchi Y, Ogihara E, Hamada M, Nishioka Y, Kimura H, Yoshidome K, Tsujimoto M, et al. 2014. Loss of histone H4K20 trimethylation predicts poor prognosis in breast cancer and is associated with invasive activity. Breast Cancer Res 16: R66.

Zee BM, Levin RS, Xu B, LeRoy G, Wingreen NS, Garcia BA. 2010. In vivo residue-specific histone methylation dynamics. I Biol Chem 285: 3341-3350.

Ziegler-Birling C, Helmrich A, Tora L, Torres-Padilla ME. 2009. Distribution of p53 binding protein 1 (53BP1) and phosphorylated H2A.X during mouse preimplantation development in the absence of DNA damage. Int J Dev Biol 53: 1003-1011. 


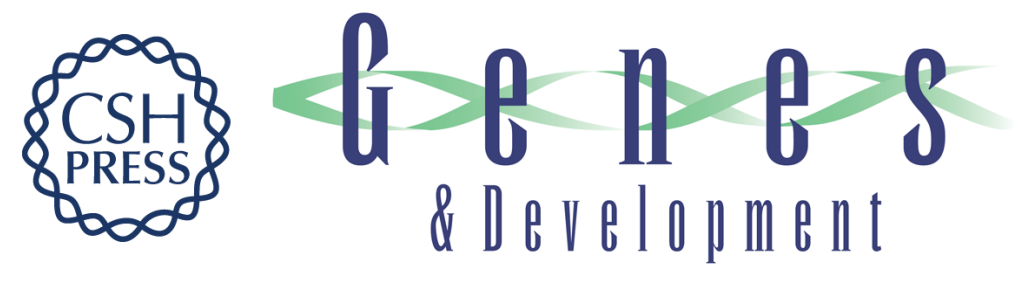

\title{
SUV4-20 activity in the preimplantation mouse embryo controls timely replication
}

\author{
André Eid, Diego Rodriguez-Terrones, Adam Burton, et al.
}

Genes Dev. 2016, 30: originally published online December 5, 2016

Access the most recent version at doi:10.1101/gad.288969.116

\section{Supplemental http://genesdev.cshlp.org/content/suppl/2016/12/05/gad.288969.116.DC1 Material \\ References This article cites 53 articles, 21 of which can be accessed free at: http://genesdev.cshlp.org/content/30/22/2513.full.html\#ref-list-1 \\ Creative This article is distributed exclusively by Cold Spring Harbor Laboratory Press for the first Commons six months after the full-issue publication date (see \\ License http://genesdev.cshlp.org/site/misc/terms.xhtml). After six months, it is available under a Creative Commons License (Attribution-NonCommercial 4.0 International), as described at http://creativecommons.org/licenses/by-nc/4.0/. \\ Email Alerting Receive free email alerts when new articles cite this article - sign up in the box at the top Service right corner of the article or click here.}

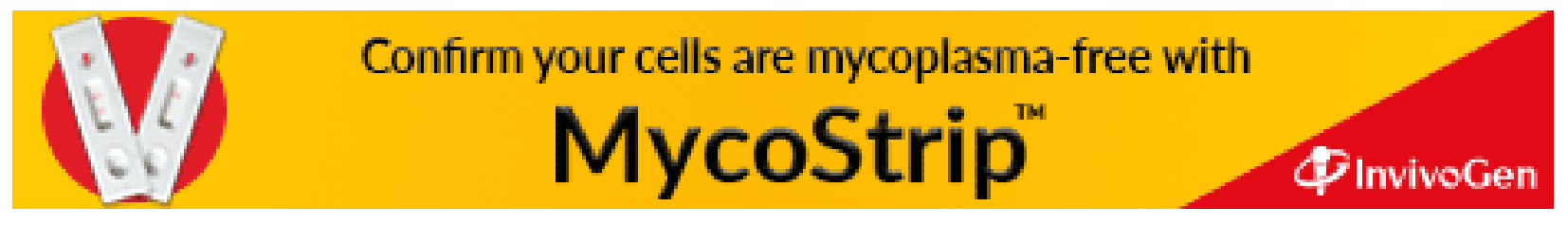

